

\title{
Experimental and numerical analysis of automotive gearbox rattle noise
}

Younes Kadmiri, Emmanuel Rigaud, Joël Perret-Liaudet, Laurence Vary

\section{To cite this version:}

Younes Kadmiri, Emmanuel Rigaud, Joël Perret-Liaudet, Laurence Vary. Experimental and numerical analysis of automotive gearbox rattle noise. Journal of Sound and Vibration, 2012, 331 (13), pp.31443157. 10.1016/j.jsv.2012.02.009 . hal-02068291

\section{HAL Id: hal-02068291 https://hal.science/hal-02068291}

Submitted on 15 Mar 2019

HAL is a multi-disciplinary open access archive for the deposit and dissemination of scientific research documents, whether they are published or not. The documents may come from teaching and research institutions in France or abroad, or from public or private research centers.
L'archive ouverte pluridisciplinaire HAL, est destinée au dépôt et à la diffusion de documents scientifiques de niveau recherche, publiés ou non, émanant des établissements d'enseignement et de recherche français ou étrangers, des laboratoires publics ou privés. 
Experimental and numerical analysis of automotive gearbox rattle noise KADMIRI Younes $^{a, b}$, RIGAUD Emmanuel $^{a}$, PERRET-LIAUDET Joël $^{a}$, VARY Laurence ${ }^{b}$

a Laboratoire de Tribologie et Dynamique des Systèmes, UMR CNRS 5513

Ecole Centrale de Lyon, Université de Lyon

36, avenue Guy de Collongue, 69134 ECULLY cedex, France

${ }^{b}$ RENAULT S.A.S.

Centre technique de Lardy

1, allée Cornuel, 91510 LARDY, France

Corresponding author: emmanuel.rigaud@ec-lyon.fr

Tel: +33472186296 - Fax: +33478433383

23 pages

1 table

16 figures 


\begin{abstract}
The aim of this work is to characterize the rattle noise of automotive gearboxes, resulting from impacts between toothed wheels of unselected gear ratios. These stereo-mechanical impacts are modeled by a coefficient of restitution which describes damping associated with the elastic deformation during the impact and the squeezing of the lubricant film. The dynamic response of loose gear firstly depends on the design parameters and the engine operating conditions. The unknown parameters are the drag torque and the coefficient of restitution. They are identified experimentally through implementation of optical encoders in an actual automotive gearbox and the operation of a specific test bench which replicates the automotive power train. Models of the different drag torque sources are validated from analysis of the free damped response of the drivelines. The coefficient of restitution and its probability density function are measured from experiments under stationary operating conditions. A non linear model is built. The dynamic response of loose gear depends on the dimensionless backlash, the coefficient of restitution and a dimensionless parameter proposed to describe the rattle excitation level. Experiments under controlled excitation are performed to validate the assumptions, to confirm the ability of the parameter proposed to describe the rattle noise threshold, and to characterize the dynamic response. The non linear model predictions are fitted with the drag torque and coefficient of restitution previously identified. They are compared with measurements to demonstrate the ability of the model to predict gear rattle for any loose gear, any gearbox and any operating condition.
\end{abstract}

\title{
Keywords
}

Loose gear, non linear dynamics, impact, coefficient of restitution, drag torque 


\section{Nomenclature}

A amplitude of velocity fluctuation of the generator

$A^{\prime} \quad$ amplitude of velocity fluctuation of the driving gear

b gear face width

C drag torque

$c_{v} \quad$ equivalent viscous damping coefficient

D gear reference diameter

$D_{t} \quad$ gear tip diameter

F $\quad$ Equivalent force

$h \quad$ submerged depth of a gear

$H \quad$ amplitude of displacement fluctuation imposed by the excitation

I impulsion

I dimensionless impulsion

$I_{g} \quad$ inertia of loose gear

$I_{s} \quad$ Inertia of primary shaft

$j(t) \quad$ gear backlash

$\tilde{J}(t) \quad$ dimensionless gear backlash

$j_{s} \quad$ radial clearance between shaft and loose gear

$L \quad$ interface length

$m \quad$ equivalent mass of loose gear

$r \quad$ coefficient of restitution

$R \quad$ pin radius

$R_{1}, R_{2}$ involute radii at the pitch point

$R_{s} \quad$ shaft radius

$R(t) \quad$ reaction force applied to the loose gear

$R_{b 1}, R_{b 2}$ gear base radii of the driving pinion and the loose gear

$S$ immerged surface 


$\begin{array}{ll}T & \text { temperature } \\ V & \text { oil volume } \\ x(t) & \text { displacement of loose gear along line of action } \\ y(t) & \text { periodic displacement of driving gear } \\ Z & \text { number of teeth } \\ \varphi & \text { phase of the excitation } \\ \Lambda & \text { dimensionless excitation } \\ \mu & \text { dynamic viscosity } \\ \rho & \text { density } \\ \tau & \text { dimensionless time } \\ \omega & \text { fundamental circular frequency } \\ \Omega & \text { rotation speed }\end{array}$




\section{1- Introduction}

Acoustic comfort is an important criterion for sales of automobile manufacturers. For many years, research efforts allowed reduction of acoustic levels. Consequently, noise sources that were previously masked emerge. Gear rattle noise due to impacts between teeth of unloaded gears is particularly audible at low speed regime of the engine.

Design of conventional manual gearbox is such that all gear pairs mesh simultaneously. For each gear pair, one toothed wheel is fixed permanently to the associated shaft while the other wheel (loose gear) can rotate relative to their supporting shaft. When a gear ratio is selected, the corresponding loose gear is temporary connected to the secondary shaft. Beyond an excitation threshold, the other loose gears vibrate through their functional backlashes and contact losses occur. Their dynamic behavior is characterized by impacts on active and reverse flanks of the fixed driving gear. The successive impacts are transmitted to the housing through shafts and bearings, leading to noise emitted from the gearbox. It is widely believed that successive lighted loaded impacts do not change the dynamic behavior of the driveline and do not lead to wear, but perception of emitted noise would be associated with low quality manufacture.

For each unselected gear ratio, the key parameters in rattle noise analysis are the circular frequency and the velocity fluctuation of the driving gear, the inertia of the loose gear, the gear backlash, the drag torque, and the elastic and damping characteristics during impacts [1].

Velocity fluctuation of the driving gear is induced by torque fluctuation of the engine. It depends on the engine configuration and the operating conditions. Many investigations deal with the torsional analysis of the driveline dynamic behavior in relation with its design to attenuate gear rattle noise [2-6]. The aim is to optimize the transfer function between the engine and the gearbox input shaft. Devices such as multi-stage clutches and dual-mass flywheels are proposed to reduce vibration of the driveline by filtering torque fluctuation of the engine.

Others works remain localized on the loose gear dynamics. Mechanical parts upstream of the gearbox are not taken into account. The excitation corresponds to the velocity fluctuation of the gearbox input shaft previously obtained from torsional analysis of the whole driveline. The studied parameters are internal to the gearbox. A harmonic excitation is usually assumed [7-10]. Effects of the multi-harmonic periodical 
excitation source have also been analyzed [11, 12], as well as gear eccentricities which govern gear backlash amplitude and which are secondary internal excitation sources [13, 14].

The rattle threshold is defined as the excitation level leading to occurrence of contact losses. The inertia torque of the loose gear at a given acceleration exceeds the drag torque. Influence of the inertia has been highlighted many times [1, 3, 8, 15]. Similarly, Dogan [16] has confirmed that a high drag torque increases the rattle threshold. Unfortunately, a higher drag torque also leads to higher power losses and increases fuel consumption. Beyond the rattle threshold, the drag torque governs the dynamic response of the loose gear during the free flight. It results from several sources: windage dissipation [17], shearing which takes place at the interfaces with the shaft and the synchronizer, and churning due to partial immersion in oil. Several studies proposed formulation for the oil churning drag torque. Seetharaman $[18,19]$ developed an analytical model based on fluid mechanics to describe power losses associated with interactions of partially immersed gear with oil. For an immersed gear mesh interface, the main source of power loss is due to squeezing and pocketing of the gear pair with oil at the interface. Power loss is also due to oil drag on the sides of the gear. On the contrary, power loss that occurs during the filling of the cavity between adjacent teeth with oil and power loss due to oil drag on the periphery of the gear are negligible. Changenet [20] proposed empirical formulation from a large number of oil churning experiments.

The impacts occurring on active and reverse flanks of gears can be modeled in two different ways. The first approach describes damping and stiffness during contact. The presence of a drop of lubricant between teeth provides a damping source. Brancati [21] and Russo [22] focused on the effect of oil damping between the impacting teeth. An analytical expression of the damping coefficient has been obtained, depending primary of oil quantity and viscosity. The positive influence due to oil damping in reducing impacts amplitude has been demonstrated and experimentally verified.

Contact stiffness depends on the position of the mesh point along the line of action when impact occurs. It is also a nonlinear function of instantaneous load. For highly loaded gears, some time varying and non linear meshing stiffness formulations have been developed [23-25]. Gears operate under elastohydrodynamic regime. The lubricant film becomes almost incompressible and its effect on the meshing stiffness is negligible. For lightly loaded impacts corresponding to rattle noise, the low stiffness of 
the lubricant cannot be neglected [21]. De la Cruz described the impact load variation from modeling the lubricant film squeeze for approaching surfaces [26]. Elasticity of adjacent teeth should also be taken in account. Unfortunately, contact geometry and effective stiffness of the gear pair is very sensitive to tooth modifications and manufacturing errors [27]. So, this first approach main limitation is the difficulty of describing the dissipative and elastic characteristics of the contact during lightly loaded impacts.

The second approach uses a coefficient of restitution to characterize stereo-mechanical impacts [7-9, 28]. As transmitted torque is null, impacts are lightly loaded and contact occurs only for a very short time. Impacts are described by the generalized impact theory [29]. The coefficient of restitution depends on materials, contact geometry, operating conditions and the presence of lubricant between adjacent surfaces. For each impact, it describes damping associated with both elastic deformations of gear teeth and squeezing of the lubricant film when surfaces approach.

Finally, automotive gearbox rattle noise is still a challenging problem. The nature of the expected nonlinear dynamic response is not clearly known. Moreover, the actual values of the numerous parameters involved are not accurately identified especially the elastic and damping characteristics of impacts.

This paper reports an experimental investigation of a conventional manual automotive gearbox designed by Renault under rattle conditions. First, the gearbox is instrumented and assembled on a test bench which replicates an automobile power train. Driving and loose gears angular displacements are measured with optical encoders. Identification of key parameters is considered in detail. Coefficients of restitution of impacts are quantified inside the gearbox in actual operating conditions. Free damped response of the driveline is analyzed for different assembly versions to identify the different contributions to the drag torque applied to the loose gear. Then, a non linear numerical model is developed and presented. The dynamic response of the loose gear depends on three dimensionless parameters including the coefficient of restitution and the dimensionless backlash. A dimensionless parameter describing rattle excitation level is proposed. It combines excitation frequency and amplitude, inertia and drag torque. The input data are updated from experimental measurements. Non linear dynamic response is computed and compared with experiments performed within ranges of various neutral and drive operating conditions. The aim is to 
conclude on the ability of the proposed parameter to describe the rattle noise threshold and on the main characteristics of the dynamic response of the loose gear.

\section{2- Gearbox instrumented and test bench}

The TL4 six-speed manual gearbox designed by Renault is considered. It is composed of a primary shaft, a secondary shaft and a reverse shaft mounted on rolling elements bearings, and a differential drive. The primary shaft is designed with two fixed gears and four loose gears with sleeve synchronizer sets. The secondary shaft is designed with two loose gears, four fixed gears and the gear for the differential. Gears of the secondary shaft are partially immersed in oil to assure splash lubrication. Figure 1 displays kinematics scheme of the gearbox.

Measurement of driving and loose gears angular displacements is required. Instrumentation of the gearbox was chosen, taking into account the limited space available, the relative displacement of the loose gear within the confines of the clearance (few hundred micrometers) and the severe operating conditions like high temperature (until $50^{\circ} \mathrm{C}$ ), high rotational velocity (until $3500 \mathrm{rpm}$ ) and presence of lubricant. For the experiments performed, the second gear ratio is considered $\left(Z_{1}=19, Z_{2}=37\right)$. Two optical encoders are integrated on the driving and the loose gears. The gears fixed on the driveline, the studied loose gear and the loose gear corresponding to the engaged ratio are preserved. The other loose gears and sleeve synchronizer sets are removed. The inside temperature is measured using sensor. Accelerometers are mounted on the housing in order to measure vibratory response of the gearbox due to successive impacts generated by rattle. Emitted noise is measured with a microphone.

The instrumented gearbox is assembled on a specific test bench designed by Renault to characterize the vibratory and acoustic behavior of gearboxes. The bench replicates an automobile power train, including the clutch, the gearbox and the mechanical transmissions. The engine is replaced by an electric generator which allows control of the rotation speed of the driving gear $\bar{\Omega}$, amplitude $A$ and circular frequency $\omega$ of the excitation. The Renault TL4 gearbox is usually associated with a four cylinder four stroke engine. The main frequency of the crankshaft velocity fluctuation is twice the circular frequency. So, the input law is written as follows: 


$$
\Omega(t)=\bar{\Omega}+A \cos (\omega t)
$$

with

$$
\omega=2 \Omega(2 \pi / 60)
$$

The transmissions are connected to electric brakes delivering the torque applied to the drive wheels. The bench is placed in a semi-anechoic chamber. It has several operating modes. The generator is able to play a signal measured at the output of an engine in actual operating conditions. It is also able to play any input law chosen by the user. Figure 2 displays kinematics scheme of the test bench.

\section{3- Impacts characterization: experimental identification of coefficient of restitution}

\subsection{Preliminary analysis: effects of lubricant viscosity, sliding velocity and impacting velocity}

Impacts between a cylindrical steel pin and a steel rotating disk have been preliminary studied outside the gearbox, in order to analyze effects of lubricant viscosity, sliding velocity and impacting velocity. For this, a mechanical device has been built (see Fig. 3). Pin radius is chosen from equivalent radius defined as follows:

$$
R=\left(1 / R_{1}+1 / R_{2}\right)^{-1}
$$

$R_{1}$ and $R_{2}$ correspond to the involute radii at the pitch point. The pin is connected to a bi-blade with low stiffness allowing motion according to the vertical direction. The disk rotational motion is monitored using a brushless motor in order to vary sliding velocity between surfaces during impacts. The synchronous velocity and displacement of the pin are identified using a laser vibrometer system which operates on the Doppler principle, measuring back-scattered laser light from the moving solid. The dynamic response is characterized by flight periods and impacts with very short duration (see Fig. 4). The initial vertical distance between the pin and the disk is controlled to vary the impacting velocity in the range corresponding to impacts inside the gearbox. Disk rotational speed is chosen to vary sliding velocity between surfaces in the range corresponding to usual operating conditions. Finally, lubricant is introduced between the pin and the disk. Various oils with a wide range of dynamic viscosity are used. Indeed, the viscosity of the gearbox lubricant is particularly affected by the operating temperature $(\mu$ varies from 0.08 to 0.03 Pa.s with increasing temperature from 20 to $50^{\circ} \mathrm{C}$ ). For each impact, the coefficient of restitution is identified from the velocity just after and before impact.

$$
r=-V^{+} / V^{-}
$$


It describes the damping during both the squeezing of the lubricant film when surfaces approach, and the elastic deformation of impacting bodies. The role of the viscosity of the lubricant is confirmed. The presence of the lubricant decreases the coefficient of restitution. The higher the viscosity, the larger the dissipation is. A linear decreasing of the coefficient of restitution versus impacting velocity is also observed. On the contrary, experiments performed show that the sliding velocity has no significant effect on the coefficient of restitution.

\subsection{Measurement inside the gearbox}

The actual value of damping associated with impacts is measured directly inside the gearbox, because the chosen instrumentation seems to be appropriate to characterize in situ coefficient of restitution. the impacting velocity can be measured using encoders. Gear kinematics and dynamic response change the instantaneous contact characteristics associated to each impact. Nevertheless, impacting velocity can be measured using encoders. The choice of lubricant is imposed by problems like load-carrying capacity of gears and fuel consumption of the vehicle. Higher temperatures increase the propensity of the gearbox to rattle, so experiments are performed at $50^{\circ} \mathrm{C}$ (mean temperature of oil).

The encoders resolution is 2048 lines per revolution and signals are acquired by an analog/digital card with sampling frequency $50 \mathrm{kHz}$, so that maximum rotation speed is limited to $1500 \mathrm{rpm}$. However, dimensional analysis shows that an equivalent alternative is to vary amplitude of velocity fluctuation, in order to increase the excitation level and to sweep all operating conditions (see eq. (24)).

Experiments performed correspond to a mean rotation speed $\bar{\Omega}=750 \mathrm{rpm}$ and amplitudes of velocity fluctuation $A=50 \mathrm{rpm}, 75 \mathrm{rpm}, 100 \mathrm{rpm}$ and $125 \mathrm{rpm}$. Relative velocity between the driving and loose gears is deduced from post-processing of encoders response. Successive impacts are detected. The sign of the relative velocity just before impact allows discrimination of impacts between active flanks and impacts between reverse flanks (see Fig. 5). The high frequency data acquisition also allows measurement of impact duration. Its probability density function shows a Gaussian distribution (see fig. 6). The average duration is $1.2 \mathrm{~ms}$ and the standard deviation is $0.06 \mathrm{~ms}$. Assumption of very short impacts duration is confirmed, compared to the excitation source frequency. Figure 7 displays evolution of the coefficient of restitution 
versus impacting velocity. Responses for impacts between active flanks and for impacts between reverse flanks are identical. In the range of impacting velocities explored, a linear decreasing of the coefficient of restitution is observed. For each impacting velocity, a large dispersion of results is observed. Results from Fig. 7 are used to define the coefficient of restitution probability density function and its impact velocity dependence.

\section{4- Experimental identification of drag torque applied to the loose gear}

The motion between impacts is governed by the drag torque during the free flight period. The sources of dissipation can be decomposed into drag torque applied to the loose gear and other sources. The first one is mainly due to shearing which takes place at the interface with the shaft, and oil churning. Windage dissipation is neglected for the studied gearbox since the wheel radii are small and the driveline rotational velocity is limited to $4500 \mathrm{rpm}$. For the instrumented gearbox, an additional source is due to the optical encoder mounted on the loose gear. The other dissipation sources are oil shearing at the interfaces between the shaft and other loose gears if any, oil churning of immersed solids, and rolling element bearings dissipation. For the instrumented gearbox, an additional source is due to the optical encoder mounted on the primary shaft. Power loss at the gear mesh interfaces are neglected, because no gear ratio is engaged and no gear mesh interface is immersed.

A stationary rotation speed of the primary shaft is introduced. Then, the gearbox is disengaged from the generator. The free damped motion is measured, until motion stops. The drag torque applied to the loose gear is identified in three consecutive steps corresponding to three different assembly versions of the gearbox. First, the gearbox is drained and the instrumented primary shaft moves alone. Then, the loose gear is mounted on the secondary shaft, without encoder. At last, oil is added and experiments are performed for different operating temperatures in order to vary the oil viscosity. Figures 8,9 and 10 display velocity decay of the primary shaft for the three different assembly versions of the gearbox.

For the first assembly version, the drag torque $C_{1}$ is deduced from velocity decay. It is associated to rolling element bearings and dissipation in the encoder of the driving gear. Velocity response of the primary shaft shows an exponential decay: 


$$
\Omega=a+b \mathrm{e}^{d t} \quad(\Omega>0)
$$

The parameter $a$ is due to the torque $C_{s 1}$ associated with solid friction. The exponential decay corresponds to a torque proportional to the velocity. $C_{1}$ can be written as follows:

$$
C_{1}=C_{s 1}+c_{v 1} \Omega=-I_{s} a d+I_{s} d \Omega
$$

For the second assembly version, the total drag torque $C$ is deduced from velocity decay. The added drag torque $C_{2}$ is due to oil shearing at the interface with the secondary shaft. The added velocity decay is exponential, so $C_{2}$ is modeled by an equivalent viscous damping coefficient.

$$
C_{2}=C-C_{1}=c_{v 2} \Omega
$$

For the third assembly version, the added drag torque $C_{3}$ is due to churning of the loose gear. It is deduced from the total drag torque $C^{\prime}$. Analysis of the added dissipation shows it corresponds to a power function of the velocity:

$$
C_{3}=C^{\prime}-C_{1}-C_{2}=K \Omega^{\beta}
$$

For each operating temperature, the coefficients $c_{v 1}, c_{v 2}, K$ and $\beta$ are obtained from an optimization algorithm based on the Trust region method. The implementation of this algorithm minimizes the difference between experimental velocity decay and functions derived from eq. (4-7). The lower the temperature, the faster the deceleration of the primary shaft is, because oil viscosity and drag torque induced by shearing and churning increases. An additional experiment with the instrumented loose gear allows identification of the additional source due to the second optical encoder.

The drag torque due to oil shearing at the interface with the shaft may reasonably be modeled assuming a Couette laminar flow:

$$
C_{2}=2 \pi \mu L R_{S}^{3} \Delta \Omega / j_{S}
$$

Oil churning is mainly due to drag on the sides of the gear. For half-immersed gear considered, Seetharaman [18] writes:

$$
C_{3}=0.0256 \pi D_{t}^{4} \rho \sqrt{\mu \Omega^{3}}
$$

The predicted effect of rotation speed in eq. (9) conflicts our own experiments, because boundary conditions differ from a single gear rotating in oil. The presence of neighboring gears alters the oil drag on 
the sides of the gear. Changenet proposed empirical formulation, from several oil churning experiments with a large number of gears configurations [20]:

$$
C_{3}=\frac{1}{2} S h^{3} \rho \Omega^{2} C_{r}
$$

with

$$
C_{r}=1.366\left(\frac{h}{D_{t}}\right)^{0.45}\left(\frac{V}{D_{t}{ }^{3}}\right)^{0.1} \mathrm{Fr}^{-0.6} \mathrm{Re}^{-0.21}
$$

where the Froude and Reynolds numbers are defined by:

$$
\operatorname{Fr}=\frac{D_{t}}{2} \Omega^{2} / g \quad \operatorname{Re}=\rho b \frac{D_{t}}{2} \Omega / \mu
$$

Eq. (10) agrees well with our own experiments.

Loose gears for the third and the fourth gear ratio have been added in the gearbox, in order to test the robustness of obtained model. Corresponding drag torques have been estimated from eq. $(8,10)$ and added to previous ones, for several temperatures. The free damped motion of the driveline has been simulated. Comparison with the experimental damped motion confirms the predictive character of the proposed model.

\section{5- Dynamic model}

A non linear numerical model is developed to predict the loose gear dynamic response and to compare numerical results with experiments under controlled excitation. The dynamic response is described with a non linear single degree of freedom model displayed in Fig. 11. $x(t)$ is the equivalent displacement along the line of action corresponding to angular fluctuation of the loose gear around its theoretical position.

$$
x(t)=R_{b 2} \theta(t)
$$

$y(t)$ is the periodic displacement function taking into account the velocity fluctuation of the driving gear. $j(t)$ is the backlash between teeth. Equation of motion of the loose gear can be written in the following form:

$$
I_{g} \ddot{\theta}=-C
$$

Velocity fluctuation of the driving gear is negligible compared with average velocity, so that drag torque during free flight is assumed to be constant. Introducing eq. (13), equation of motion becomes:

$$
m \ddot{x}=-F \quad y(t)<x(t)<y(t)+j(t)
$$

with

$$
m=I_{g} / R_{b 2}^{2}
$$




$$
F=C / R_{b 2}
$$

$m$ is the equivalent mass of the loose gear and $F$ is associated with the drag torque. Load transmitted by impacts is very light. So, successive impacts do not change the dynamic behavior of the driveline. Assuming a harmonic excitation, $y(t)$ is written as follows:

$$
y(t)=H \cos (\omega t-\varphi)
$$

$\omega$ is the circular frequency of the excitation and corresponds to the second harmonic of the circular frequency of the driving gear. $H$ and $\varphi$ are respectively the displacement amplitude and the phase. Stereo-mechanical impacts are described with the coefficient of restitution $r$ :

$$
\dot{x}_{t^{+}}-\dot{y}_{t^{+}}=-r\left(\dot{x}_{t^{-}}-\dot{y}_{t^{-}}\right)
$$

with

$$
t^{+}=t^{-}+\delta t \quad \delta t \rightarrow 0
$$

Superdot denotes derivative respect to dimensionless time, and $t^{+}$and $t^{-}$denote short time after and before impact. In addition, a limit impulse velocity is defined for which there are no rebounds anymore. Therefore, condition leading to a permanent contact between loose and driving gears is expressed. Beyond this limit velocity, contact between gears is preserved as long as the reaction force applied to the loose gear $R(t)$ remains positive. Thus, for the active flank, the following condition is verified:

$$
0<R(t)=F+m \ddot{y}(t)
$$

and for the reverse flank:

$$
0>R(t)=F+m \ddot{y}(t)
$$

A dimensional analysis of equations of motion shows that all parameters depend on three fundamental units (mass, length and time). The number of variables necessary to describe the rattle is $6(m, F, R, H, j, \omega)$. From, the Vaschy-Buckingham theorem (or $\pi$ theorem), the analysis of the loose gear dynamics can be done using 3 dimensionless numbers. Parameters chosen are the coefficient of restitution $r$, the dimensionless backlash $\tilde{\jmath}(\tau)$ and the dimensionless parameter $\Lambda$ which is characteristic of the excitation level. $\Lambda$ corresponds to the ratio between inertial force imposed to the loose gear and the force $F$ associated with the drag torque. It depends on the equivalent mass $m$, the amplitude of the excitation $H$, the fundamental circular frequency $\omega$, and the force $F$ :

$$
\tilde{\jmath}(\tau)=j(t) / H
$$




$$
\Lambda=m H \omega^{2} / F
$$

\section{6- Experimental rattle noise threshold}

Experiments performed correspond to successive mean rotation speeds $\bar{\Omega}=250 \mathrm{rpm}, \bar{\Omega}=500 \mathrm{rpm}$, $\bar{\Omega}=750 \mathrm{rpm}, \bar{\Omega}=1000 \mathrm{rpm}$. Operating temperature is $50^{\circ} \mathrm{C}$. The equivalent mass of the loose gear is $\mathrm{m}=0.38 \mathrm{~kg}$. For each test, the drag torque is estimated from the previous measurements (see Table 1 ). The main source corresponds to the optical encoder mounted on the loose gear. A sweeping of velocity fluctuation amplitude $A$ is introduced, from 0 to $150 \mathrm{rpm}$.

$$
\Omega(t)=\bar{\Omega}+A \cos (\omega t)
$$

The signal delivered by the generator is controlled, but, the clutch suited between the generator and the gearbox induces a nonlinear transfer function between the generator and the driving gear, especially when no gear ratio is engaged. Dynamics of the driving gear does not match the generator signal and the excitation source is disrupted. The amplitude of the excitation is:

$$
H=R_{b 1} A^{\prime} / \omega
$$

where $A^{\prime}$ corresponds to velocity fluctuation amplitude of the driving gear measured with the encoder.

The occurrence of the rattle can be detected in several ways. The relative velocity between the driving and loose gears is deduced from encoders' measurement and allows detection of the first impacts. Furthermore, effects on these impacts can be detected from accelerometers mounted on the housing. A drastic and instantaneous change in noise emitted from the gearbox is also observed. The corresponding instantaneous value of velocity fluctuation $A^{\prime}$ is measured to estimate the dimensionless parameter $\Lambda$ associated to the rattle threshold. Table 1 presents the measured the rattle threshold for the different operating rotation speeds. The higher the rotation speed, the faster the threshold is. Nevertheless, the rattle noise threshold corresponds to an almost constant value of the dimensionless parameter $\Lambda$.

Beyond the rattle threshold, an impulsion is transmitted to gears for each impact, corresponding to the transmitted force time integral:

$$
I=\int_{t^{-}}^{t^{+}} F \mathrm{~d} t
$$

Impulsion depends on relative velocity between gears just before and after impact: 


$$
I=m\left(V^{+}-V^{-}\right)=-m V^{-}(1+r)
$$

Dimensionless impulsion is defined as follows:

$$
\tilde{I}=I /(m H \omega)
$$

Figure 12 displays the dimensionless impulsions vs. dimensionless parameter $\Lambda$. Positive values correspond to impact between active flanks and negative values correspond to impacts between reverse flanks. Dynamic response of the loose gear is characterized by impacts on both flanks, for all operating conditions studied. The mean rotation speed, the drag torque applied to the loose gear and the range swept by the parameter $A^{\prime}$ are different for each operating condition. So, the range swept by the parameter $\Lambda$ differs for each experiment. For $\bar{\Omega}=250 \mathrm{rpm}, A^{\prime}$ rises from 0 to $170 \mathrm{tr} / \mathrm{min}(0<\Lambda<0.64)$. For $\bar{\Omega}=1000 \mathrm{rpm}, \Lambda$ firstly rises from $\Lambda=0$ to $\Lambda=0$.7. Then, a sudden change in the velocity amplitude of the fixed gear $A^{\prime}$ is observed because of the clutch dynamic behavior, and $\Lambda$ varies from $\Lambda=1.2$ to $\Lambda=2.35$. The range between 0.7 and 1.2 is not explored. Nevertheless, for the common ranges, the superposition of the maps shows that they are almost identical. This confirms the validity of the dimensionless parameter $\Lambda$ describing the dimensionless excitation level.

\section{7- Loose gear dynamics: experiments and model validation}

\subsection{Neutral}

Further experiments performed correspond to stationary operating conditions. The constant mean rotation speed is $\bar{\Omega}=750 \mathrm{rpm}$ and the constant velocity fluctuation amplitudes are $A=100 \mathrm{rpm}$ and $A=150 \mathrm{rpm}$. Operating temperature is $50^{\circ} \mathrm{C}$. The dynamic response of the loose gear is compared with simulation obtained with the dynamic model. The excitation considered in the model is the velocity fluctuation of the driving gear measured by the encoder. Backlash value is measured from gears metrology and operating center distance. A probability density function is provided for the coefficient of restitution. It is deduced from previous experimental results. Impacting velocity dependence is assumed. Drag torque is also deduced from previous models.

Figure 13 displays experimental and simulated relative velocities between the loose and the driving gear. Figure 14 corresponds to experimental and simulated Poincaré maps, which display impulsion versus phase 
for each impact. Numerical results agree with experimental ones. Relative velocities are very close. The nonlinear model can efficiently predict the occurrence of successive impacts, as well as their amplitude. Characteristics of the loose gear dynamic response are also well predicted. For $A=100 \mathrm{rpm}$, dynamics is close to a 1T-periodic response with 2 impacts per period of excitation, that is to say 4 impacts per rotation. An impact between active flanks succeeds an impact between reverse flanks. Impulsion amplitudes of the two impacts are similar. The phase of impacts between reverse flanks predicted is slightly different from experiments.

The dynamic response is also well predicted by the numerical model when increasing the velocity fluctuation with the electric generator. The driving gear dynamics is characterized by emergence of several harmonics of the excitation frequency, leading to occurrence of several successive impacts on the same flank with distinct phases.

\subsection{Gear ratio engaged}

For the next experiments, the third gear ratio is engaged. A similar approach is used to analyze the dynamic response of the loose gear. Operating conditions are similar to previous ones $(\bar{\Omega}=750 \mathrm{rpm}, A=100 \mathrm{rpm}$, $\mathrm{T}=50^{\circ} \mathrm{C}$ ). The main difference is the estimation of the drag torque due to oil shearing at the interface with the rotating secondary shaft, depending on the differential speed. Figures 15 and 16 display the comparison between experimental and simulated results. Dynamics corresponds to a 1T-periodic response with 2 impacts per period of excitation: an impact between active flanks succeeds an impact between reverse flanks. The occurrence of successive impacts and their amplitude are well predicted by the numerical model.

Several similar experiments have been performed. Results confirm the ability of the numerical model to predict the characteristics of the non linear dynamics of the loose gear, whatever the gearbox configuration.

\section{8- Conclusion}


Beyond an excitation threshold, the dynamic response of the loose gears is characterized by successive impacts transmitted to the housing through the shafts and bearings, and leading to rattle noise emitted from the gearbox. The analysis of the dynamic response of the loose gear can be conducted from three dimensionless parameters: the coefficient of restitution that describes the damping during both the squeezing of the lubricant film when surfaces approach, and the elastic deformation of impacting bodies, the dimensionless gear backlash and the dimensionless parameter $\Lambda$ that describes the overall level of excitation and that takes into account the inertia of the loose gear, the amplitude of velocity fluctuation, the excitation frequency and the drag torque applied to the loose gear.

Preliminary experiments confirmed the important role of the lubricant viscosity in the impacts damping. They also showed the coefficient of restitution depends solely on the impacting velocity and it is insensitive to sliding velocity. The unknown parameters have been identified from the operation of a specific bench designed by Renault and the instrumentation of the driving and loose gears with optical encoders. The impact duration measurement validates the modeling of impacts by a coefficient of restitution. Its probability density function is a Gaussian function taking account of its impact velocity dependence and the viscosity of the lubricant at the actual operating temperature. Models describing the different contributions to drag torque applied to the loose gear have also been validated. The other parameters governing rattle noise depend on gearbox design (inertia, gear backlash, eccentricity, etc.), they are controlled by the test bench generator (mean rotation speed) or they are measured by the optical encoder fixed on the driving pinion (velocity fluctuation spectral content).

Experiments performed confirm that the equivalent excitation level can be described using the dimensionless parameter $\Lambda$. It governs both the rattle threshold and, beyond the threshold, the time history of impacts and the impulsion amplitudes, whatever the chosen operating condition. Time histories and Poincaré maps for stationary operating conditions show that the dynamic response of the loose gear corresponds to a $1 T$ periodic response with 2 impacts per period of excitation. Time history and amplitudes of impulsions obtained from the non linear dynamic model agree with experiments. Results demonstrate that the model is predictive for the neutral as well as if a gear ratio is engaged. From this work, 
characterization of gear rattle may be considered, for any loose gear, any gearbox and any operating conditions.

\section{Aknowledgement}

This work has been supported by Renault S.A.S.

\section{References}

[1] A.Rust, F.K. Brandl, G.E. Thien, Investigations into gear rattle phenomena - key parameters and their influence on gearbox noise, IMechE, C404/001, 113-120, 1990.

[2] T. Sakai, Y. Doi, K. Yamamoto, T. Ogasawara, M. Narita, Theoretical and experimental analysis of rattling noise of automotive gearbox, SAE Technical Paper, 810773, 1-10, 1981.

[3] R. Singh, H. Xie, R.J. Comparin, Analysis of automotive neutral gear rattle, Journal of Sound and Vibration, 131 (2), 177-196, 1989.

[4] C. Padmanabhan, R. Singh, Influence of clutch design on the reduction and perception of automotive transmission rattle noise, Noise-con 93, Williamsburg, VA, 1993.

[5] A. Szadkowski, Mathematical model and computer simulation of idle gear rattle, SAE Technical Paper, 910641, 81-95, 1991.

[6] C.K. Chae, K.M. Won, K.T. Kang, Measurement of transmission rattle sensitivity and calculation of driveline torsional vibration for gear rattle analysis, SAE Technical Paper, 2005-01-1785, 2005.

[7] G. Weidmer, G. Lechner, Rattling vibrations in automotive transmissions, JSME International Conference on Motion and Power Transmissions, Hiroshima, 37-42, 1991.

[8] F.Pfeiffer, Modelling problems of rattling in gearboxes, JSME International Conference on Motion and Power Transmissions, Hiroshima, 43-48, 1991.

[9] K. Karagiannis, F. Pfeiffer, Theoretical and experimental investigations of gear-rattling, Nonlinear Dynamics, 2 (5), 367-387, 1991.

[10] M. Wang, W. Zhao, R. Manoj, Numerical modelling and analysis of automotive transmission rattle, Journal of Vibration and Control, 8 (7), 921-943, 2002. 
[11] M. Barthod, B. Hayne, J.L. Tébec, J.C. Pin, Experimental study of dynamic and noise produced by a gearing excited by a multi-harmonic excitation, Applied Acoustics, 68 (9), 982-1002, 2007.

[12] J. Perret-Liaudet, Y. Kadmiri, E. Rigaud, Automotive rattle noise and effects of the multi-harmonics periodical excitation source, $37^{\text {th }}$ International Congress and Exposition on Noise Control Engineering, October 26-29, Shanghai, 2008.

[13] J. Perret-Liaudet, E. Rigaud, Some effects of gear eccentricities on automotive rattle noise, ASME International Design Engineering Technical Conferences (IDETC/CIE2007), 10th International Power Transmission and Gearing Conference, Paper 34794, 561-568, Las Vegas, 2007.

[14] J. Otewill, S. Neild, R. Wilson, Intermittent gear rattle due to interactions between forcing and manufacturing errors, Journal of Sound and Vibration, 321 (3-5), 913-935, 2009.

[15] C. Delprete, C. Rosso, Numerical analysis of gear rattle. SAE Technical Paper, 2005-01-1786, 2005.

[16] S.N. Dogan, J. Ryborz, B. Bertsche, Rattling and clattering noise in automotive transmissions Simulation of drag torque and noise, Tribology and Interface Engineering Series, 43, 109-121, 2003.

[17] P. Dawson, Windage loss in larger high-speed gears, Proceedings of the Institution of Mechanical Engineers, Part A: Power and Process Engineering 198 (1), 51-59, 1984.

[18] S. Seetharaman, A. Kahraman, Load-independent spin power losses of a spur gear pair: Model formulation, Journal of Tribology, 131 (2), 022201, 2009.

[19] S. Seetharaman, A. Kahraman, Load-independent spin power losses of a spur gear pair: Experiments and model validation, Journal of Tribology, 131 (2), 022202, 2009.

[20] C. Changenet, X. Oviedo-Marlot, P. Velex, Power loss predictions in geared transmission using thermal networks - Application to a six-speed manual gearbox, Journal of Mechanical Design, 128, 618-625, 2006.

[21] A. Kahraman, R. Singh, Interactions between time varying mesh stiffness and clearance non linearity in a geared system, Journal of Sound and vibration, 146 (1), 135-156, 1991.

[22] R. Brancati, E. Rocca, R. Russo, An analysis of the automotive driveline dynamic behaviour focusing on the influence of the oil squeeze effect on the idle rattle phenomenon, Journal of Sound and Vibration 303, 858-872, 2007. 
[23] R. Russo, R. Brancati, E. Rocca, Experimental investigations about the influence of oil lubricant between teeth on the gear rattle phenomenon, Journal of Sound and Vibration, 321, 647-661, 2009.

[24] G. Blankenship, R. Singh, A new gear mesh interface dynamic model to predict multi dimensional force coupling and excitation, Mechanism and Machine Theory, 30 (1), 43-57, 1995.

[25] S. Theodossiades, S. Natsiavas, Non linear dynamics of gear pair systems with periodic stiffness and backlash, Journal of Sound and vibration, 229 (2), 287-310, 2000.

[26] M. De la Cruz, S. Theodossiades, H. Rahnejat, An investigation of manual transmission drive rattle, Proceedings IMechE, Part K: Journal of Multi-body Dynamics 224, 167-181, 2010.

[27] S. Li, Effects of machining errors, assembly errors and tooth modifications on loading capacity, loadsharing ratio and transmission error of a pair of spur gears, Mechanism and Machine Theory, 42 (6), 698-726, 2007.

[28] Y. Kadmiri, J. Perret-Liaudet, E. Rigaud, L. Polac, Automotive rattle noise: some theoretical results in relation with the retained coefficient of restitution law for modelling teeth impacts, JSME International Conference on Motion and Power Transmissions, Sendai, 174-179, 2009.

[29] W. Goldsmith, Impact: The theory and physical behaviour of colliding solids, London, Edward Arnold Ltd., 1960. 


\section{Table}

Table 1: Rattle noise threshold value.

\section{List of figures}

Figure 1: kinematic scheme of the Renault TL4 gearbox.

Figure 2: Kinematic scheme of the test bench.

Figure 3: Mechanical device.

Figure 4: Pin velocity (a) and displacement (b) responses.

Figure 5: Relative velocity between driving and loose gears.

Figure 6: Comparison between probability density function of the impact duration and Gaussian distribution with mean $1.2 \mathrm{~ms}$ and standard deviation $0.06 \mathrm{~ms}$.

Figure 7: Coefficient of restitution $r$ vs. impacting velocity for $A=50 \mathrm{rpm}(),. 75 \mathrm{rpm}(\square), 100 \mathrm{rpm}(\mathrm{o})$ and $125 \mathrm{rpm}(\mathrm{x})$.

Figure 8: $1^{\text {st }}$ assembly version. Comparison between velocity response of the primary shaft (o) and function derived from the proposed model (-).

Figure 9: $2^{\text {nd }}$ assembly version. Comparison between velocity response of the primary shaft (o) and function derived from the proposed model (-).

Figure 10: $3^{\text {rd }}$ assembly version. Comparison between velocity response of the primary shaft for $T=55^{\circ} \mathrm{C}(\mathrm{o})$, $T=50^{\circ} \mathrm{C}(\square), T=40^{\circ} \mathrm{C}(\bullet), T=30^{\circ} \mathrm{C}(\Delta)$ and functions derived from the proposed model ( $\left.\square\right)$.

Figure 11: Rattle gear model.

Figure 12: Dimensionless impulsions vs. dimensionless parameter $\Lambda . \bar{\Omega}=250 \mathrm{rpm}$ (a), $\bar{\Omega}=500 \mathrm{rpm}$ (b), $\bar{\Omega}=750 \mathrm{rpm}(\mathrm{c})$ and $\bar{\Omega}=1000 \mathrm{rpm}(\mathrm{d})$.

Figure 13: Relative velocity between loose and driving gears. Comparison between experimental $(a, c)$ and simulated (b, d) responses. Neutral, $\bar{\Omega}=750 \mathrm{rpm}, A=100 \mathrm{rpm} \mathrm{(a,b)} \mathrm{and} A=150 \mathrm{rpm}(\mathrm{c}, \mathrm{d})$.

Figure 14: Poincaré maps: Impulsion vs. phase. Comparison between experimental $(a, c)$ and simulated $(b$, d) responses. Neutral, $\bar{\Omega}=750 \mathrm{rpm}, A=100 \mathrm{rpm} \mathrm{(a,} \mathrm{b)} \mathrm{and} A=150 \mathrm{rpm}(\mathrm{c}, \mathrm{d})$. 
Figure 15: Relative velocity between loose and driving gears. Comparison between experimental (a) and simulated (b) responses. $3^{\text {rd }}$ gear ratio engaged, $\bar{\Omega}=750 \mathrm{rpm}, A=100 \mathrm{rpm}$.

Figure 16: Poincaré maps: Impulsion vs. phase. Comparison between experimental (a) and simulated (b) responses. $3^{\text {rd }}$ gear ratio engaged, $\bar{\Omega}=750 \mathrm{rpm}, A=100 \mathrm{rpm}$. 


\begin{tabular}{|c|c|c|c|c|}
\hline & $\bar{\Omega}=\mathbf{2 5 0} \mathbf{~ r p m}$ & $\bar{\Omega}=\mathbf{5 0 0} \mathbf{~ r p m}$ & $\bar{\Omega}=\mathbf{7 5 0} \mathbf{~ r p m}$ & $\bar{\Omega}=\mathbf{1 0 0 0} \mathbf{~ r p m}$ \\
\hline $\boldsymbol{\omega}\left(\mathbf{r a d ~ s}^{-1}\right)$ & 52.3 & 104.6 & 156.9 & 209.2 \\
\hline $\boldsymbol{A}^{\prime}\left(\mathbf{r a d ~ s}^{-1}\right)$ & 9.95 & 5.24 & 4.19 & 3.14 \\
\hline $\boldsymbol{H}(\mathbf{m m})$ & 4.83 & 1.27 & 0.68 & 0.38 \\
\hline $\boldsymbol{C}(\mathbf{N ~ m})$ & 0.739 & 0.821 & 0.893 & 0.964 \\
\hline $\boldsymbol{F}(\mathbf{N})$ & 14.5 & 16.1 & 17.5 & 18.9 \\
\hline$\Lambda$ & 0.35 & 0.34 & 0.37 & 0.34 \\
\hline
\end{tabular}

Table 1: Rattle noise threshold value. 




Fig. 1: kinematic scheme of the Renault TL4 gearbox. 

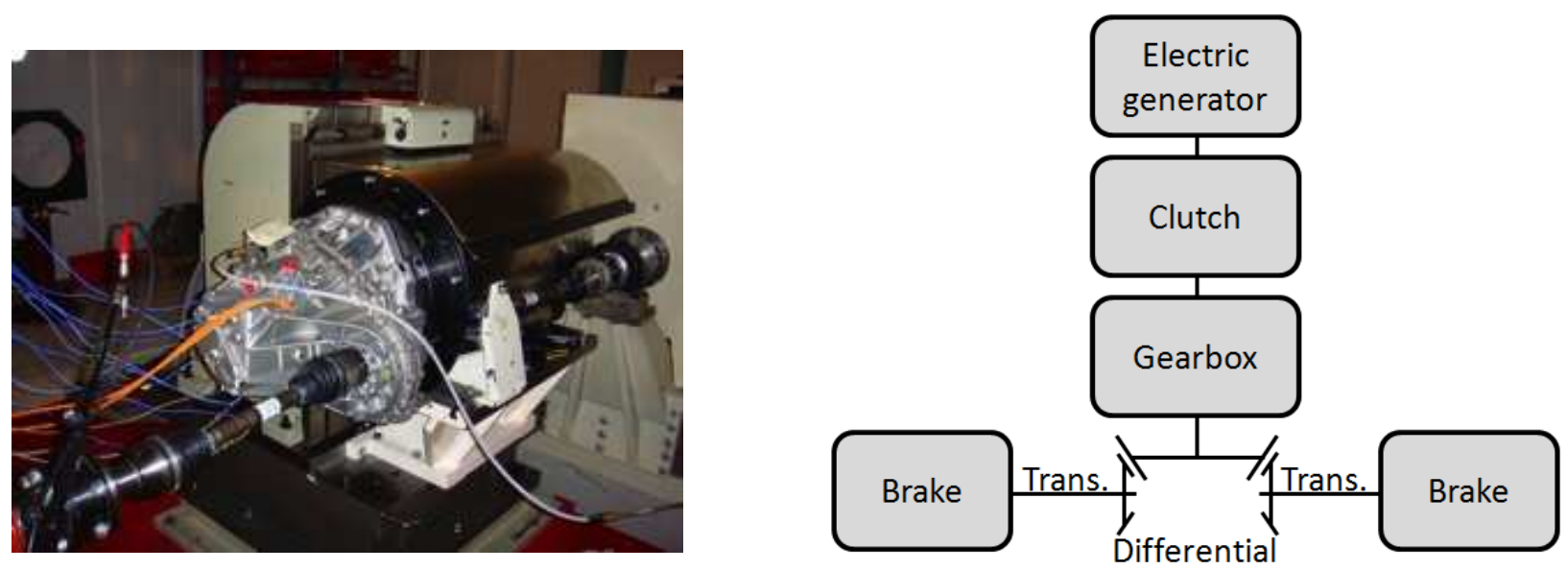

Fig. 2: Kinematic scheme of the test bench. 


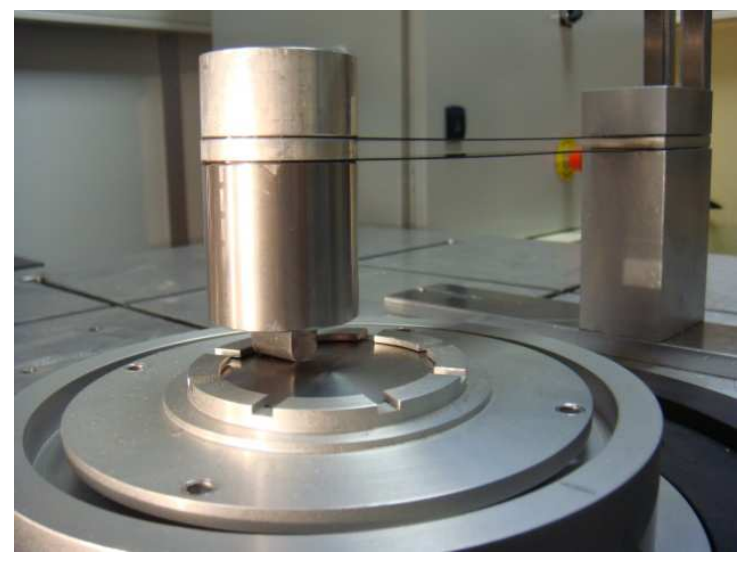

Fig. 3: Mechanical device. 
(a)

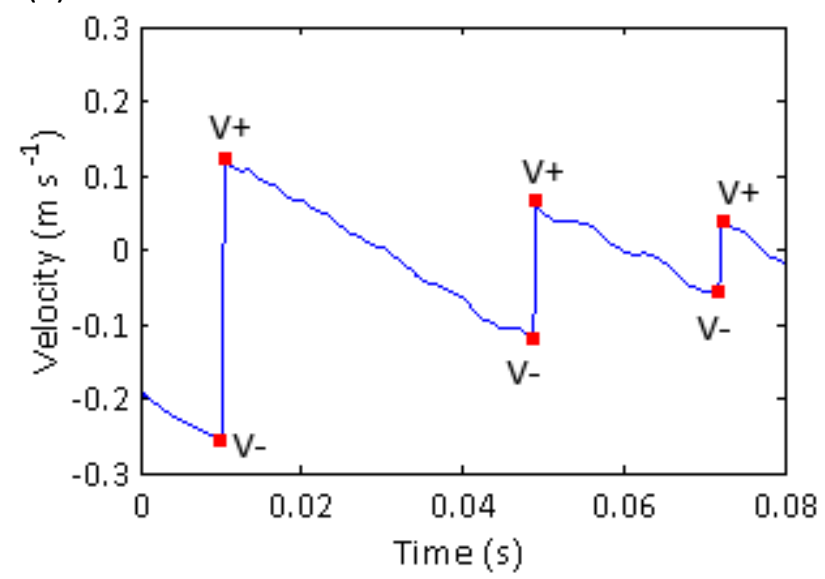

(b)

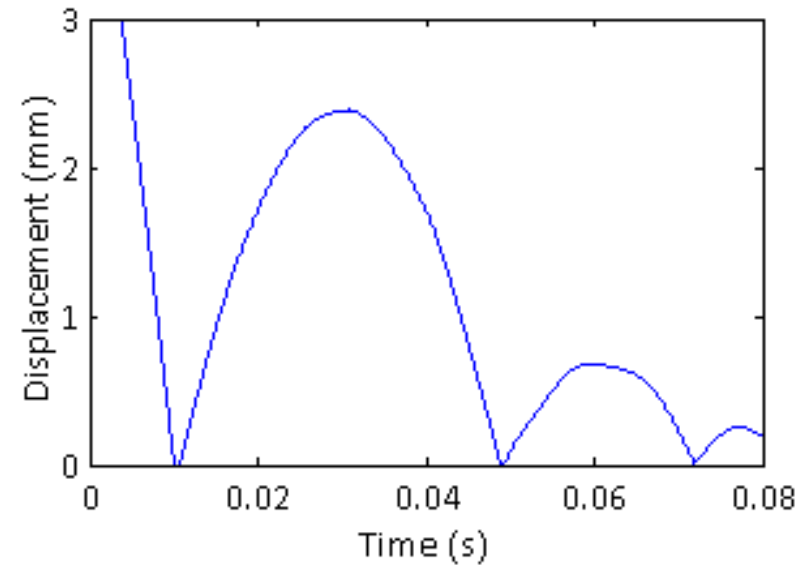

Fig. 4: Pin velocity (a) and displacement (b) responses. 


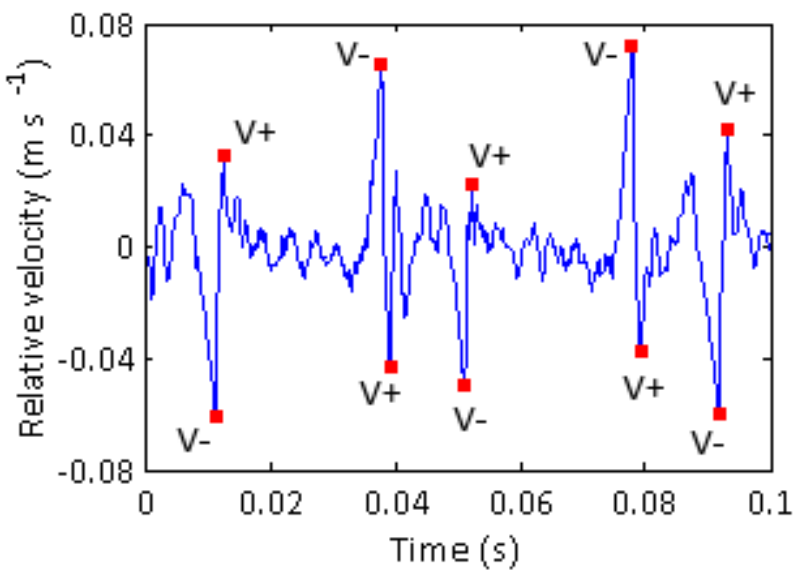

Fig. 5: Relative velocity between driving and loose gears. 


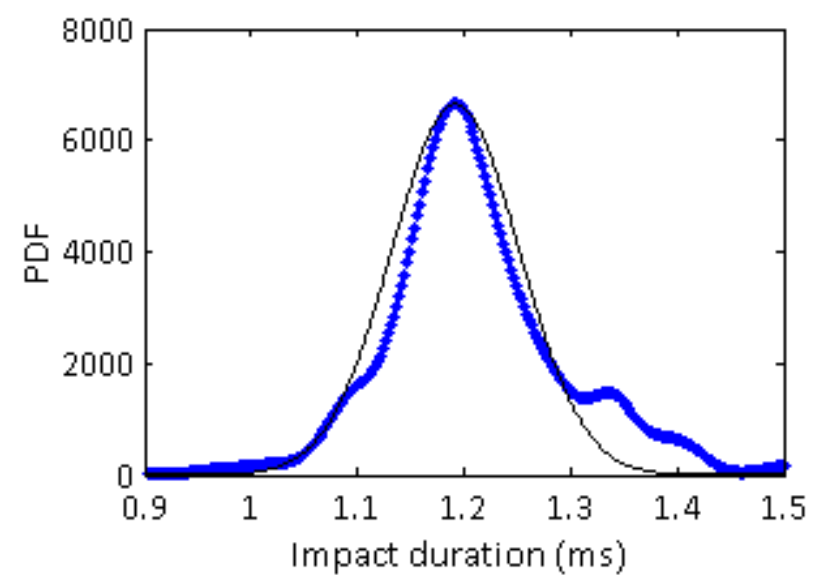

Fig. 6: Comparison between probability density function of the impact duration and Gaussian distribution with mean $1.2 \mathrm{~ms}$ and standard deviation $0.06 \mathrm{~ms}$. 




Fig. 7: Coefficient of restitution $r$ vs. impacting velocity for $A=50 \mathrm{rpm}(),. 75 \mathrm{rpm}(\square), 100 \mathrm{rpm}(0)$ and $125 \mathrm{rpm}(\mathrm{x})$. 


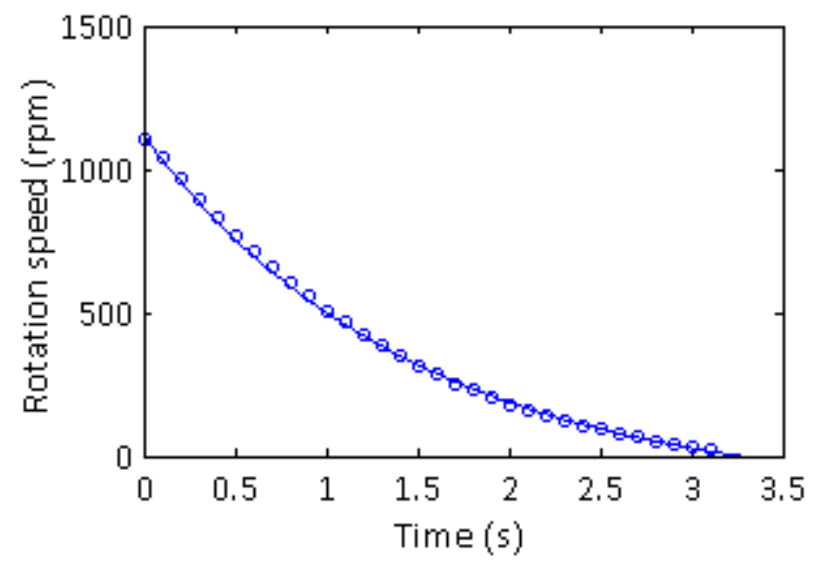

Figure 8: $1^{\text {st }}$ assembly version. Comparison between velocity response of the primary shaft (o) and function derived from the proposed model ( - ). 


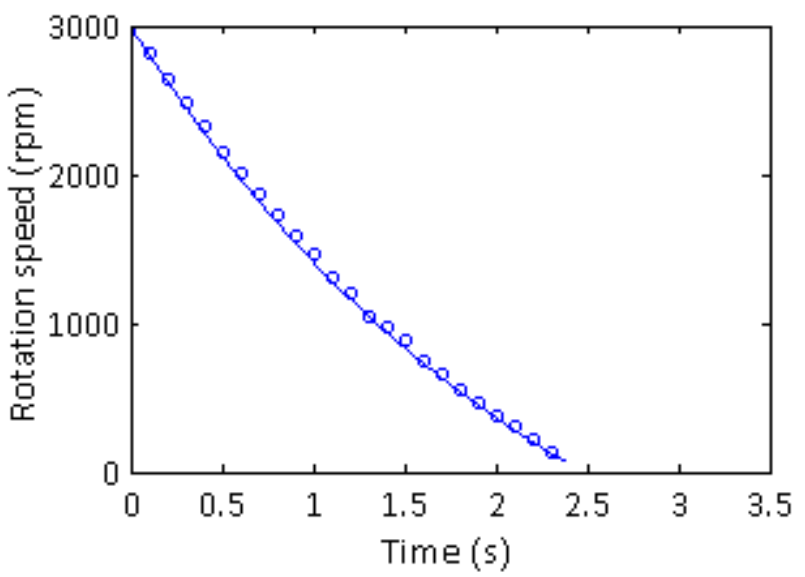

Figure 9: $2^{\text {nd }}$ assembly version. Comparison between velocity response of the primary shaft (o) and function derived from the proposed model ( - ). 


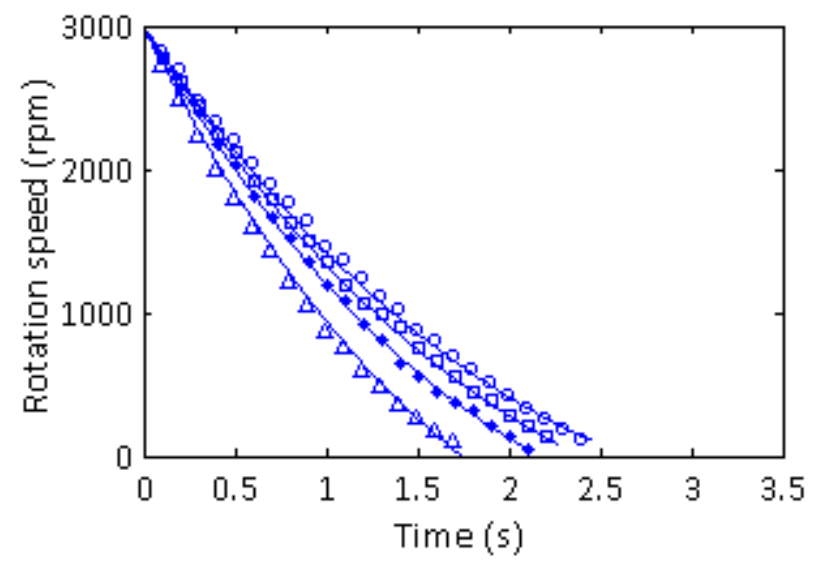

Figure 10: $3^{\text {rd }}$ assembly version. Comparison between velocity response of the primary shaft for $T=55^{\circ} \mathrm{C}(0)$, $T=50^{\circ} \mathrm{C}(\square), T=40^{\circ} \mathrm{C}(\bullet), T=30^{\circ} \mathrm{C}(\Delta)$ and functions derived from the proposed model ( $\longrightarrow$ ). 


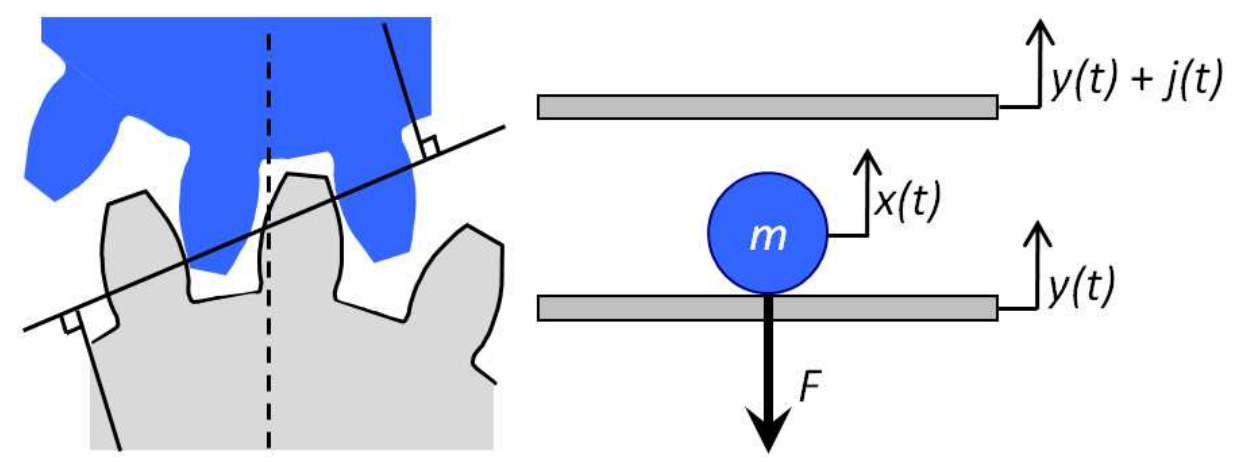

Fig. 11: Rattle gear model. 
(a)

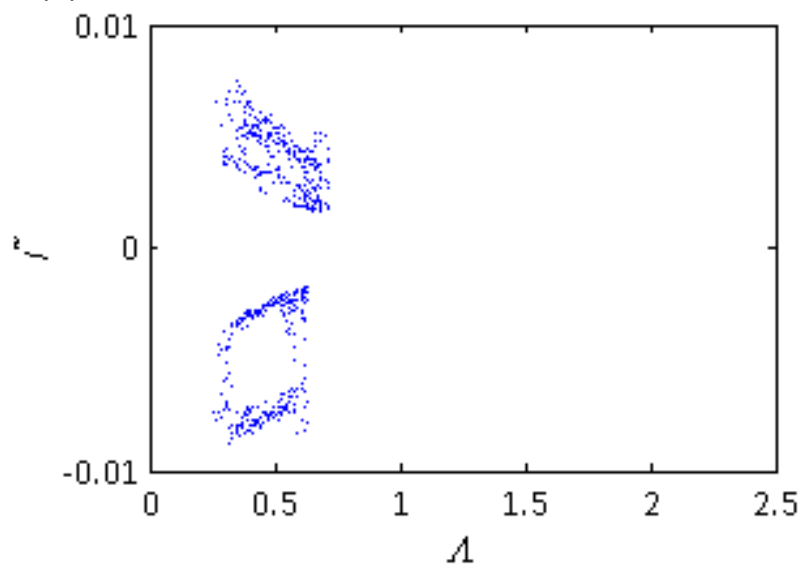

(c)

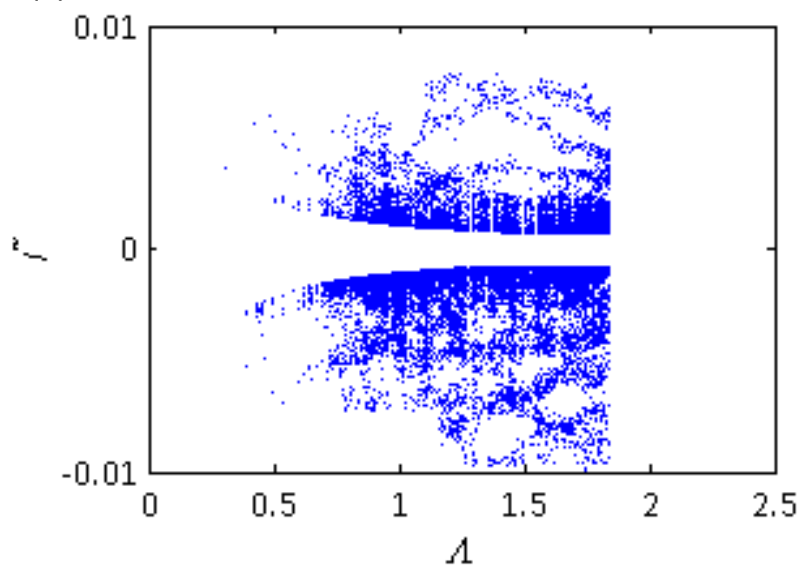

(b)

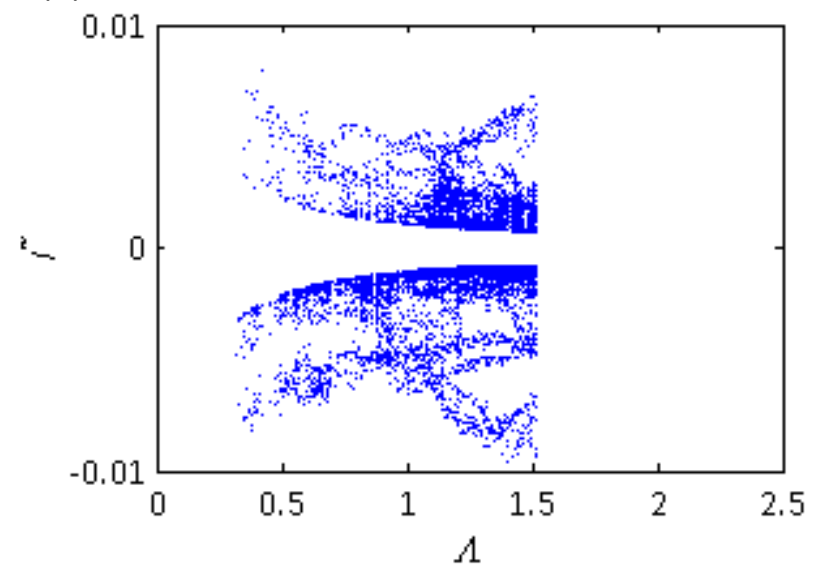

(d)



Fig. 12: Dimensionless impulsions vs. dimensionless parameter $\Lambda . \bar{\Omega}=250 \mathrm{rpm}(\mathrm{a}), \bar{\Omega}=500 \mathrm{rpm}$ (b), $\bar{\Omega}=750 \mathrm{rpm}(\mathrm{c})$ and $\bar{\Omega}=1000 \mathrm{rpm}(\mathrm{d})$. 
(a)

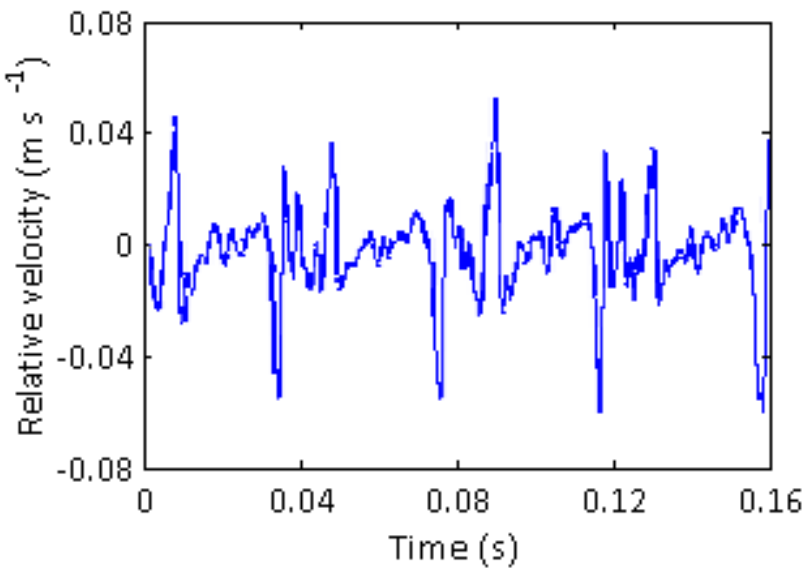

(c)

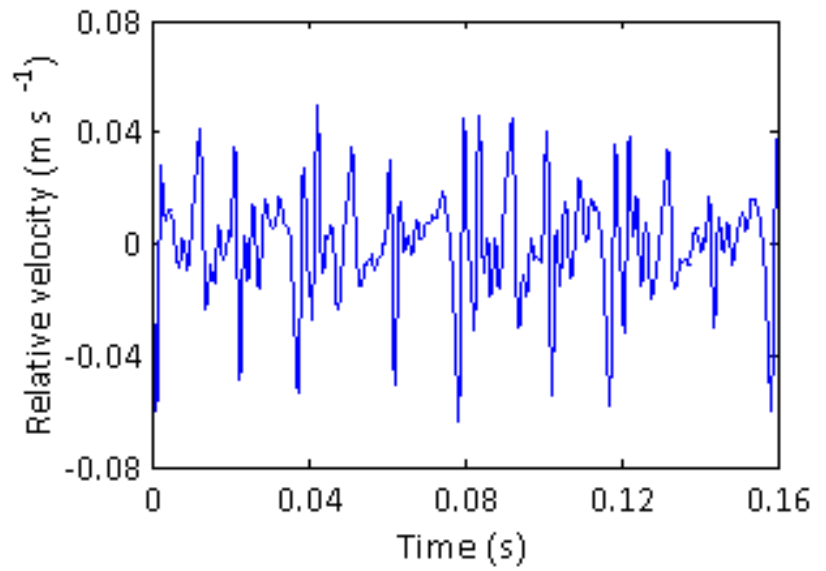

(b)

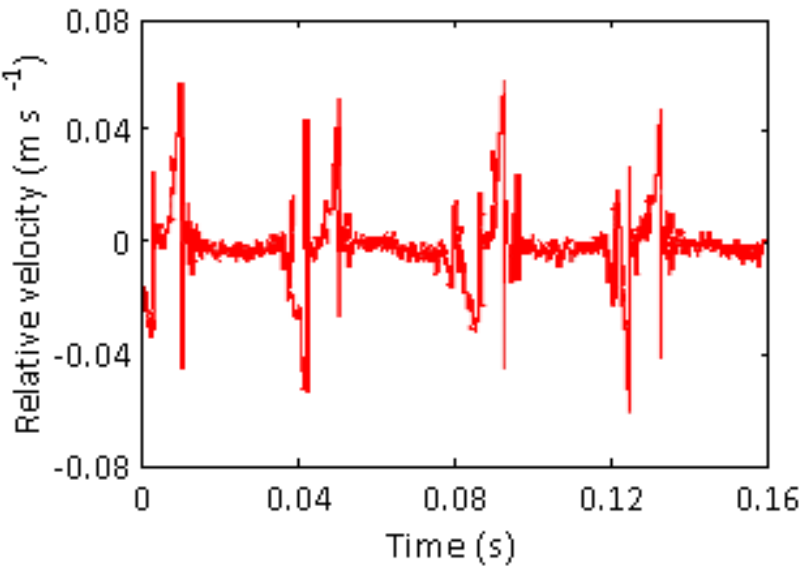

(d)

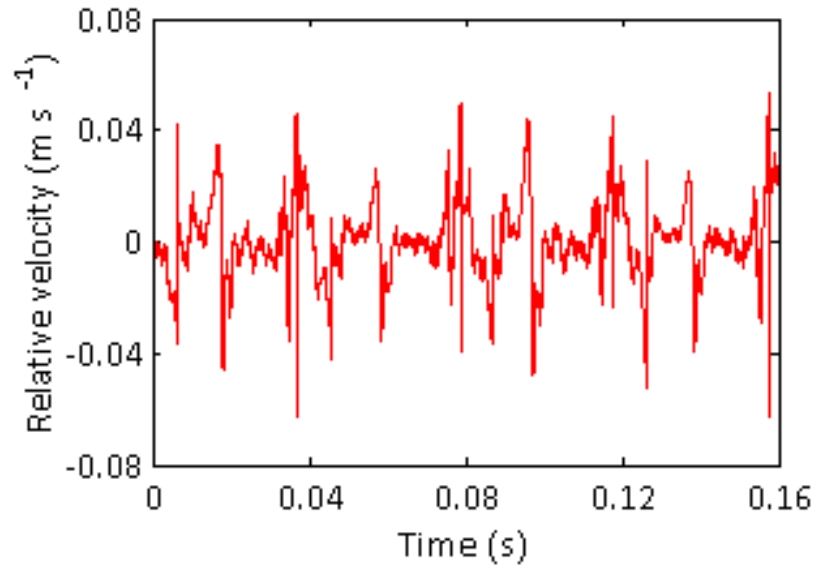

Fig. 13: Relative velocity between loose and driving gears. Comparison between experimental $(a, c)$ and simulated (b, d) responses. Neutral, $\bar{\Omega}=750 \mathrm{rpm}, A=100 \mathrm{rpm}(\mathrm{a}, \mathrm{b})$ and $A=150 \mathrm{rpm}(\mathrm{c}, \mathrm{d})$. 
(a)

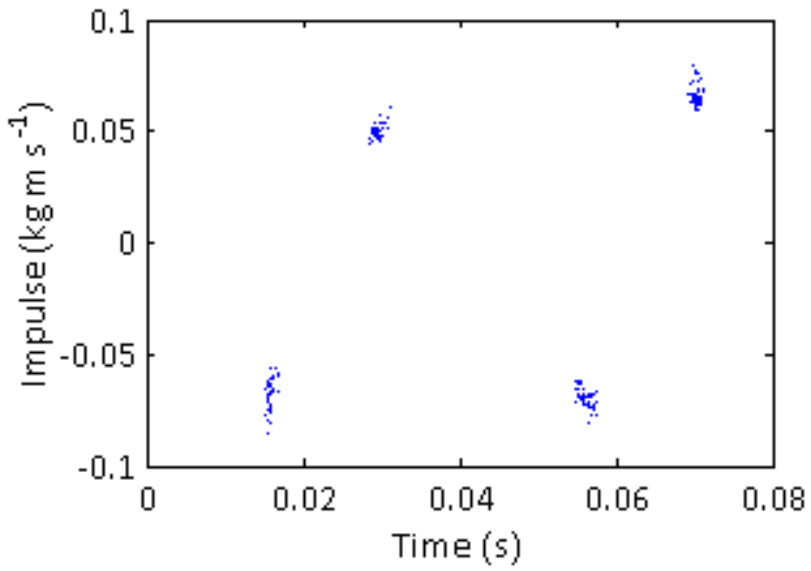

(c)

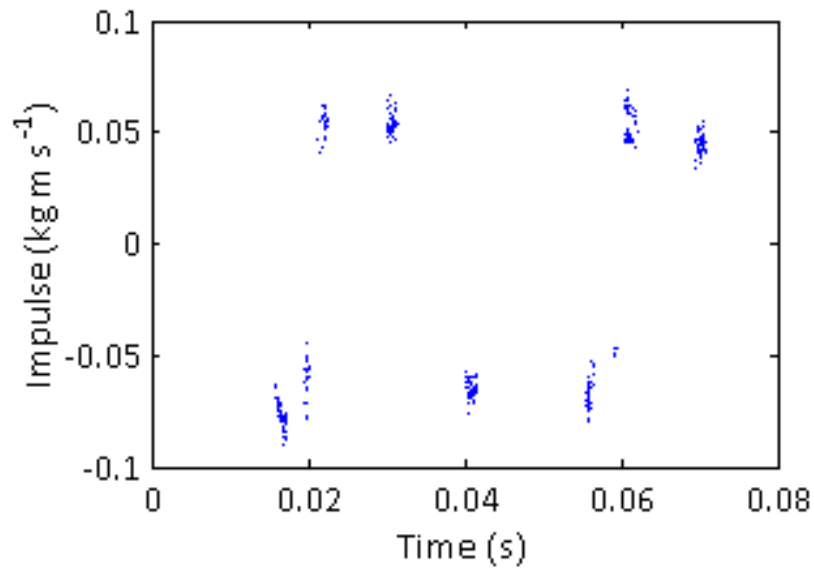

(b)

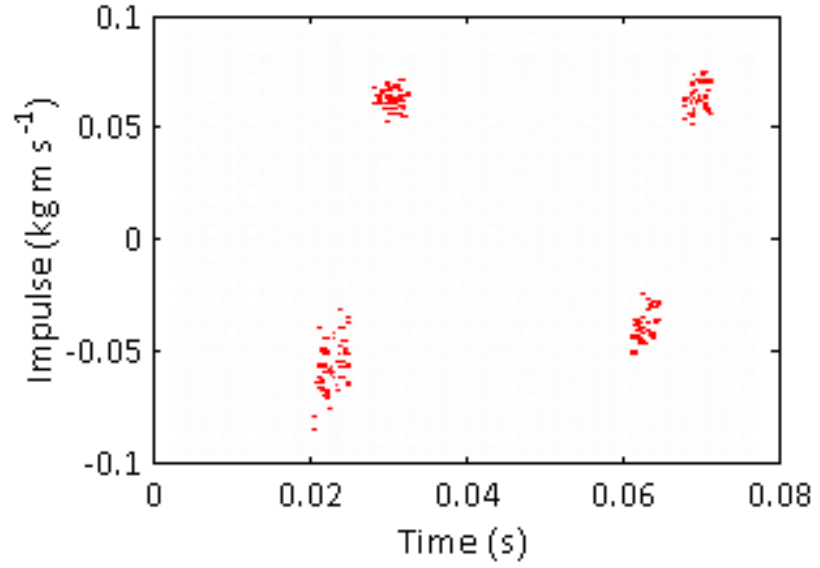

(d)

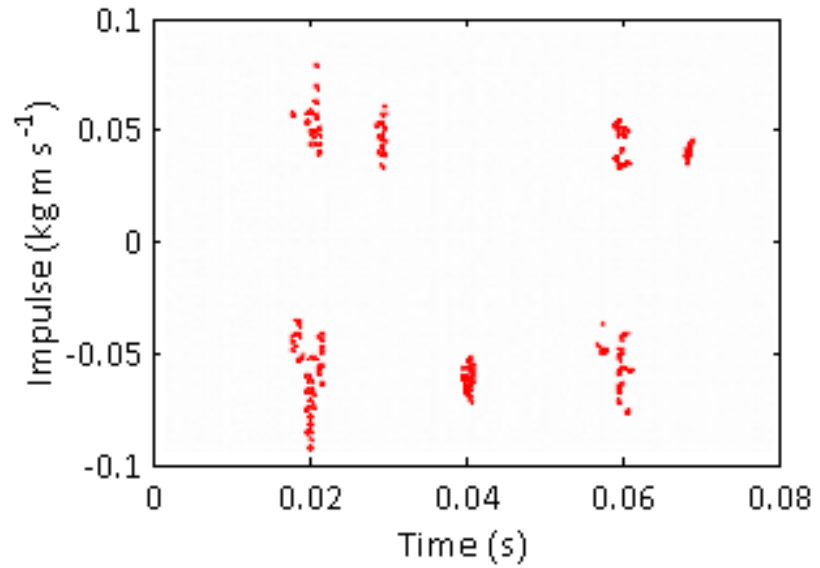

Fig. 14: Poincaré maps: Impulsion vs. phase. Comparison between experimental $(a, c)$ and simulated $(b, d)$ responses. Neutral, $\bar{\Omega}=750 \mathrm{rpm}, A=100 \mathrm{rpm}(\mathrm{a}, \mathrm{b})$ and $A=150 \mathrm{rpm}(\mathrm{c}, \mathrm{d})$. 
(a)

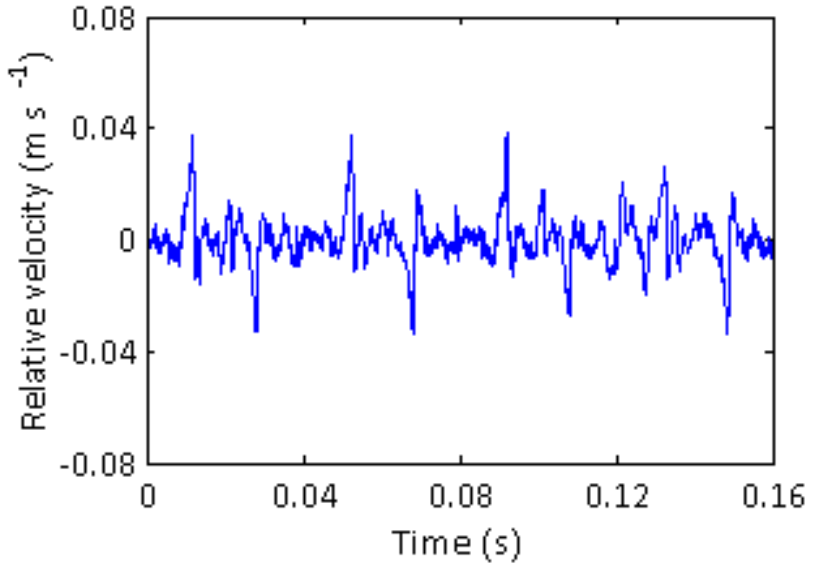

(b)



Fig. 15: Relative velocity between loose and driving gears. Comparison between experimental (a) and simulated (b) responses. $3^{\text {rd }}$ gear ratio engaged, $\bar{\Omega}=750 \mathrm{rpm}, A=100 \mathrm{rpm}$. 
(a)

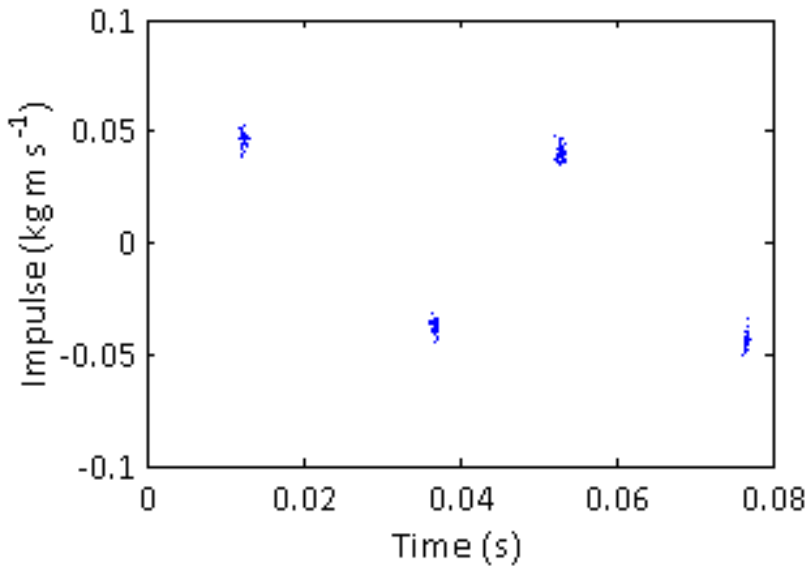

(b)

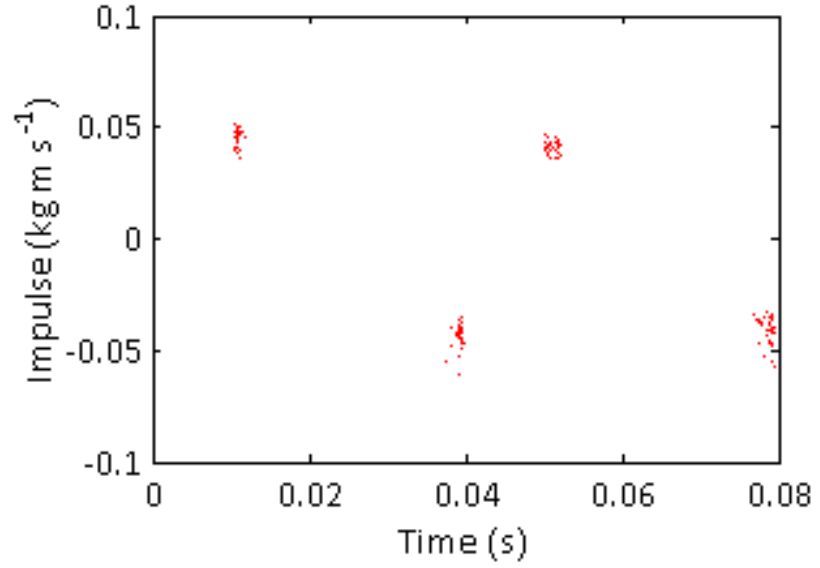

Fig. 16: Poincaré maps: Impulsion vs. phase. Comparison between experimental (a) and simulated (b) responses. $3^{\text {rd }}$ gear ratio engaged, $\bar{\Omega}=750 \mathrm{rpm}, A=100 \mathrm{rpm}$. 